\title{
Pharyngocutaneous fistula repair: case report and review of management strategies
}

\author{
Raj Nagarkar ${ }^{1}$, Gauri Sayaji Kokane ${ }^{2}$, Ashvin Wagh $^{2}$, Shrikant Vanjari ${ }^{2}$, Sachin Bansod ${ }^{2}$
}

${ }^{1}$ HCG Manavata cancer centre, Nashik, Maharashtra, India

${ }^{2}$ Department of Head and neck surgical oncology, HCG Manavata cancer centre, Nashik, Maharashtra, India

Received: 22 June 2017

Revised: 25 July 2017

Accepted: 26 July 2017

\section{*Correspondence:}

Dr. Gauri Sayaji Kokane,

E-mail: gaurikkn@gmail.com

Copyright: (C) the author(s), publisher and licensee Medip Academy. This is an open-access article distributed under the terms of the Creative Commons Attribution Non-Commercial License, which permits unrestricted non-commercial use, distribution, and reproduction in any medium, provided the original work is properly cited.

\begin{abstract}
Incidence of post chemoradiation salvage laryngectomy complication rate is $3 \%-65 \%$. It is most common but most annoying complication after salvage laryngectomy for surgeon to manage. When conservative measures fail to repair the fistula surgical means have to be considered. But even after surgical correction it takes time to heal due to local conditions. Here we present a case of surgical repair of pharyngocutaneous fistula and review of various management strategies.
\end{abstract}

Keywords: PCF, Pharyngocutaneous, Fistula, SCM Flap

\section{INTRODUCTION}

Pharyngocutaneous fistula (PCF) is most common but challenging complication after salvage laryngectomy. Its incidence ranges from 3\%-65\%. ${ }^{1,2}$ Mostly PCF occurs within 7-13 postoperative days. Its management is sometime very troublesome. Some fistulas can be managed conservatively but persistent fistulae usually require surgical repair. Conservative management options include debridement, regular dressings, ryles tube feeding and also exclusion of primary or residual neoplasm. We have reported an interesting case of PCF and its closure using local SCM flap and also reviewed various management strategies in repair of PCF.

\section{CASE REPORT}

57 year old female reported to HGC Manavata Cancer Centre with chief complaint of food particles and saliva leaking through skin over right side of lower neck region. Patient was a known case of carcinoma larynx and she had received radical chemo-radiation 3 years back and then she had a recurrent disease on PET scan after 1 year for which she underwent salvage laryngectomy. She presented with complaint of saliva and food particles leaking through the neck wound site after 3 months. On examination there was evidence of presence of Pharyngocutaneous fistula. Initially it was managed conservatively by regular dressings. Also feeding gastrostomy was performed. Inspite of conservative management the fistula was persistent. Size and location of fistula was confirmed with contrast CT scan preoperatively. There was e/o linear $10 \times 3 \mathrm{~mm}$ pharyngocutaneous fistula over right side, approximately $27 \mathrm{~mm}$ superolateral to the tracheostomy insertion. It was repaired surgically using local sternocleidomastoid (SCM) flap. Intraoperatively IJV was ruptured due to extreme fibrosis around SCM and IJV. Post operatively there was leak from surgical site for which a cuffed tracheostomy tube was reinserted and kept for 5 days. Healing was satisfactory and PCF was successfully repaired with minimum post-operative complications. 


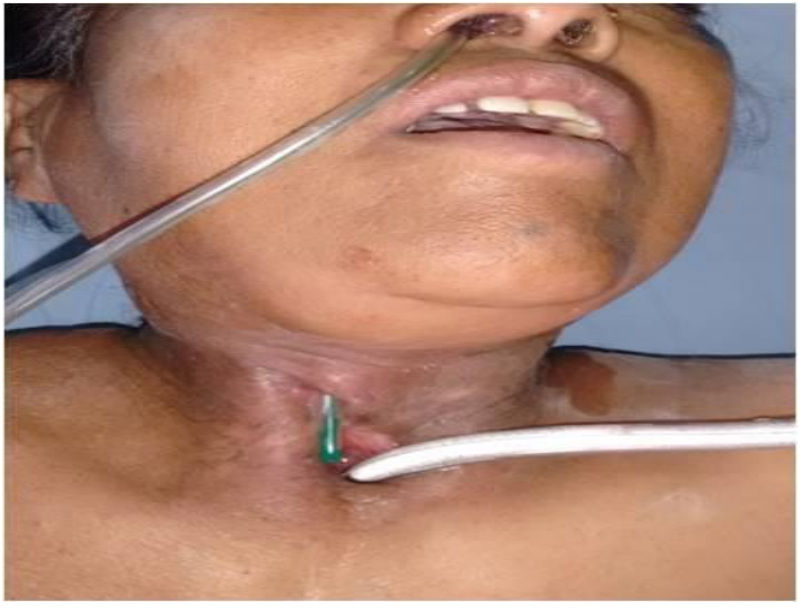

Figure 1: Intra-operative photograph showing pharyngocutaneous fistula.

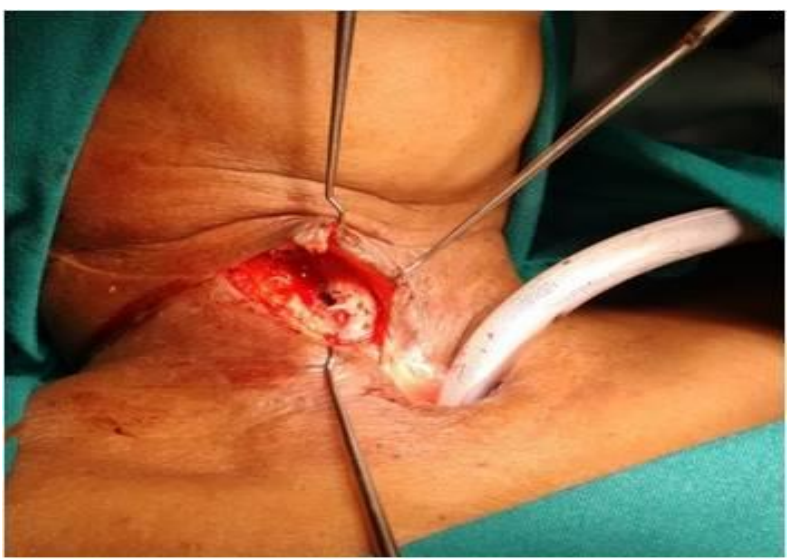

Figure 2: Intra-operative photograph demonstrating inadequacy of pharyngeal mucosa.

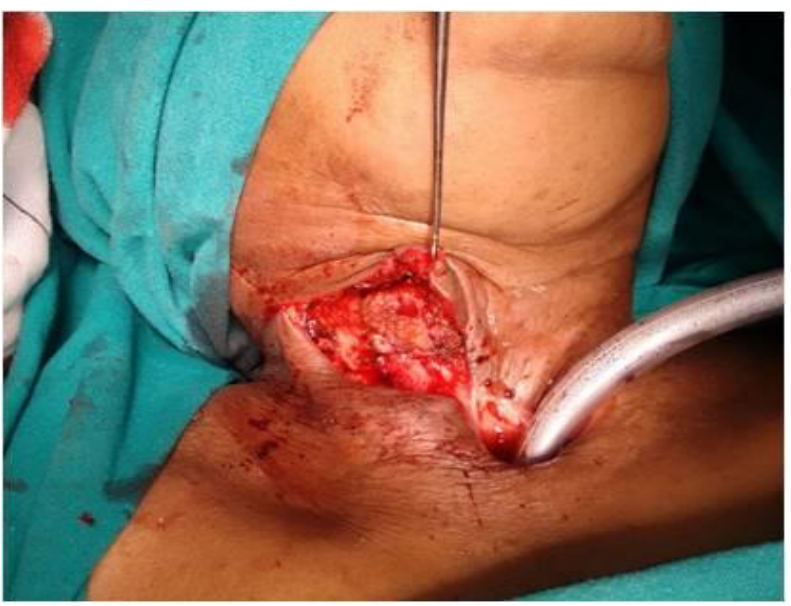

Figure 3: Mobilisation of local SCM flap for defect closure.

\section{DISCUSSION}

Most preferred management option for carcinoma of larynx is radical chemoradiation in order to preserve organ function i.e. to maintain natural voice of patient and swallowing function. But in recurrent carcinoma of larynx, salvage laryngectomy remains the only choice of management. $^{3-5}$ Patient who has already received radiation; tissues are very fragile and there is compromised vascularity of the tissue due to radiation induced fibroatrophy which compromises the postoperative healing because of this pharyngocutaneous fistula remains the frequent complication after salvage laryngectomy. ${ }^{6}$ Systemic diseases like diabetes, hypothyroidism and under nourishment further compromises the healing status. Incidence of post chemoradiation salvage laryngectomy complication rate is $3 \%-65 \%$. Usually patient presents with fistula in 7-13 days after surgery, our patient presented almost after 3 months of surgery. Our patient had hypothyroidism and also she was underweight. Conservative means in management includes, prevention of saliva accumulation, local debridement and dressing, Ryles tube feeding, adequate nutrition and antibiotic Nutritional level should be monitored by albumin level and hemoglobin level of patient. ${ }^{7}$ If conservative measures fail to close the fistulous tract then surgical options should be sought. Decision regarding surgical option for closure depends on thorough assessment of skin laxity, fistula size, amount of mucosa left over, presence or absence of strictures. In this case there were no strictures, Skin was adequate and due to the small size of defect it was planned to achieve two layer closure. Czerny and Mikulicz were first to use cervical flap in pharyngoesophageal and cervical esophageal reconstruction in 1877 and 1886 respectively. 1940 's Wooke in the early 1940's used anterior neck skin in a staged procedure for reconstruction of such defects. After 1960's distant flaps were developed such as deltopectoral flap by Bakamjian, pectoralis major myocutaneous flap by Aryian. Free radial forearm flap was later used by Harii in 1985. Anterolateral lateral thigh flap and fasciocutaneous scapular free flaps have also been used in management of pharyngocutaneous fistula. Guha classified PCF into 3 types according to their size, local wound condition and local skin condition also he advocated management strategies for each type. ${ }^{8}$ Type 1 fistula is less than $0.5 \mathrm{~cm}$ and should be repaired in Two layers locally, Type 2 fistula is size greater than $0.5 \mathrm{~cm}$ but less than $2 \mathrm{~cm}$ and should be repaired by one layer locally and one distantly, The distant flap may be DP or PMMC. Type 3 fistula is greater than $2 \mathrm{~cm}$, in which both layers were repaired distantly. Here both DP and PMMC used from the same side. ${ }^{8}$ Bootz used free jejunal flap for reconstruction in $1990 .{ }^{9}$ In our case the defect was $10 \times 3 \mathrm{~mm}$ which was quite small eventhough we had closed fistula with local sternocleidomastoid flap because of availability of inadequate pharyngeal mucosal layer as well as radiation fibrosis making closure more challenging. The use of the SCM muscle was first reported by Jianu in 1908 as a method to reanimate a paralyzed face. ${ }^{10}$ Muscle and myocutaneous flaps based on the SCM muscle have been well described by Owens. ${ }^{11}$ Usually SCM flaps have been used in closure of non-malignant defects, But we have used for closure of 
fistula in a post malignant condition. Another surgical option for closure is an island submental flap. ${ }^{12}$ The majority of the fistulas appear between 7 and 13 postoperative days. In different studies it is 40 postoperative days to 3 months but it is logical to optimize the surgical bed first before surgical repair. In our case the average time period for surgical repair was 5 months. Still the timing for surgical repair of a fistula remains unclear. Fink Ds used endoscopic approach in management of PCF in five patients successfully.

\section{CONCLUSION}

Systematic approach in management of pharyngocutaneous fistula plays key role. Careful preoperative analysis and treatment planning is a crucial factor. In our consideration there is no standard categorization of fistula repair as it may appear smaller defect but the local factor can always make surgeon to rethink on plan of treatment as in our case even though size of fistula not large but we have to revise the treatment plan on table due to in adequacy of pharyngeal mucosa and versatile SCM flap was used.

Funding: No funding sources Conflict of interest: None declared

Ethical approval: Not required

\section{REFERENCES}

1. Dirven R, Swinson BD, Gao K, Clark JR. The assessment of pharyngocutaneous fistula rate in patients treated primarily with definitive radiotherapy followed by salvage surgery of the larynx and hypopharynx. Laryngoscope. 2009;119(9):1691-5.

2. Johansen LV, Overgaard J, Elbrond O. Pharyngocutaneous fistulae after laryngectomy. Influence of previous radiotherapy and prophylactic metronidazole. Cancer. 1988;61(4):673-8.

3. Eisbruch A, Lyden T, Bradford CR, Dawson LA, Haxer MJ, Miller AE, et al Objective assessment of swallowing dysfunction and aspiration after radiation concurrent with chemotherapy for head- and-neck cancer. Int $\mathbf{J}$ Radiat Oncol Biol Phys. 2002;53(1):23-8.

4. Hillman RE, Walsh MJ, Wolf GT, Fisher SG, Hong WK: Functional outcomes following treatment for advanced laryngeal cancer; Ann Otol Rhinol Laryngol Suppl. 1998;172:1-27.

5. Lazarus CL, Logemann JA, Pauloski BR, Colangelo LA, Kahrilas PJ, Mittal BB, et al. Swallowing disorders in head and neck cancer patients treated with radiotherapy and adjuvant chemotherapy. Laryngoscope. 1996;106(9):1157-66.

6. Delanian S, Lefaix JL. The radiation-induced fibroatrophic process: therapeutic perspective via the antioxidant pathway. Radiother Oncol. 2004;73(2):119-31.

7. Önder T, Bekir A, Ergen D. Repair of a large pharyngocutaneous fistula with the free dorsalis pedis flap. Eur J Gen Med. 2007;4(1):39-43

8. Guha G, Saha S, Kundu I. Surgical Repair of Postlaryngectomy Pharyngocutaneous Fistulas. Indian J Otolaryngol Head Neck Surg. 2007;59:1037.

9. Bootz F, Müller GH Repair of salivary fistulae after laryngectomy. Clin Otolaryngol Allied Sci. 1990;15(4):299-302.

10. Jianu J. Paralizie faciale dupa extirparea unei turmoi a parotidei, trata prin operatia Dlui Gomoiu. Bull Mem Soc De Chir de Bucharest. 1908;102:377-86.

11. Owens N. A compound neck pedicle designed for the repair of massive facial defects: formation, development and application. Plast Reconstr Surg. 1955;15:369-89.

12. Janssen DA, Thimsen DA. The extended submental island lip flap: An alternative for esophageal repair. Plast Recons Surg. 1998;102:835-8.

Cite this article as: Nagarkar R, Kokane GS, Wagh A, Vanjari S, Bansod S. Pharyngocutaneous fistula repair- case report and review of management strategies. Int J Otorhinolaryngol Head Neck Surg 2017;3:1120-2. 